\title{
AGE-DEPENDENT DECLINE IN ERYTHROCYTE ACETYLCHOLINESTERASE ACTIVITY: CORRELATION WITH OXIDATIVE STRESS
}

\author{
Rashmi Jha, Syed Ibrahim Rizvi*
}

\author{
Department of Biochemistry, University of Allahabad, Allahabad 211002, India \\ e-mail: sirizvi@gmail.com
}

Received: July 10, 2009; Accepted: September 7, 2009

Key words: Aging/Acetylcholinesterase/Oxidative stress/Erythrocyte/Membrane

Background: Oxidative stress hypothesis offers a mechanism for the aging process and its involvement in other pathologies such as diabetes and neurodegenerative diseases like Alzheimer. AChE activity in erythrocytes may be considered as a marker of central cholinergic status. The present study was undertaken to (i) determine the activity of erythrocyte $\mathrm{AChE}$ as a function of human process (ii) correlate $\mathrm{AChE}$ activity with oxidative stress during human aging.

Material and Methods: Blood was collected from healthy subjects $(n=37) 22-82$ years. Erythrocyte AChE activity, MDA and plasma antioxidant capacity in terms of FRAP was measured spectrophotometrically.

Results: There was a marked decrease in AChE activity with increasing age. The reduction in activity of AChE correlated well with increased lipid peroxidation and a decrease in FRAP values.

Conclusion: Decreased antioxidant defense, and alteration in membrane rheology during aging process both may contribute towards decreased activity of $\mathrm{AChE}$ in erythrocyte membrane. This finding may help in explaining the neuronal complications taking place under conditions of oxidative stress, aging, and dementia.

\section{INTRODUCTION}

Aging is an inevitable biological process and has been defined as the progressive accumulation of diverse deleterious changes with time that increases the chance of disease and death. The oxidative stress hypothesis offers a possible mechanistic explanation of aging process and plays an important role in Alzheimer's ${ }^{1}$ and other neurodegenerative diseases ${ }^{2}$. In human aging and dementia, multiple neurotransmitter systems appear to be compromised $^{3,4}$. An age-related decline in cholinergic function is thought to be partially responsible for short-term memory disorders during senescence. The major marker of cholinergic metabolism is the activity of the hydrolytic enzyme acetylcholinesterase (AChE) that makes possible precise temporal control of synaptic activation by rapidly hydrolyzing neurotransmitter acetylcholine $(\mathrm{ACh})$ into acetate and choline ${ }^{5}$.

It is known that the activity of AChE decreases with aging in various cerebral areas ${ }^{6}$ and synaptic plasma membranes ${ }^{7}$. Inhibition of AChE results in severe cholinergic toxic signs caused by increased concentration of acetylcholine at cholinergic nerve-nerve and nerve-muscle synapses. Despite the fact that, the biological role of the acetylcholinesterase present in the erythrocyte membrane is unknown, this enzyme is reported to have many properties similar to those of the purified form obtained from brain tissues ${ }^{8}$. AChE activity in erythrocytes may be considered as a marker of central cholinergic status ${ }^{9}$.

Many in vitro studies have indicated that several parameters of blood are negatively affected by increased oxidative stress and aging. It is also known that AChE activity is inhibited by free radicals and increased oxidative stress ${ }^{10}$. We have recently reported an age dependent increase in lipid peroxidation index MDA and a decline in the total antioxidant status of plasma ${ }^{11,12}$. The aim of the present study was to investigate the effect of human aging on erythrocyte membrane-bound $\mathrm{AChE}$ and determine the correlation between markers of oxidative stress namely: lipid peroxidation and antioxidant status of plasma.

\section{MATERIALS AND METHODS}

The study was carried out on 37 normal healthy subjects of both sexes between 22 and 82 years of age. None of the subjects studied had been taking antioxidant supplementation and none smoked or had acute or chronic diseases or were receiving prescription medication. All individuals were healthy, without arterial hypertension, diabetes mellitus, asthma, cancer or tuberculosis and were well nourished. The subjects gave their informed consent and agreed to participate in the study and donation of blood samples. The protocol of study was in conformity with the guidelines of the Institutional Ethical Committee.

Human venous blood from healthy volunteers was collected in heparin tubes. Blood samples were centrifuged at $4{ }^{\circ} \mathrm{C}$ for 10 minutes at $100 \mathrm{~g}$ to remove plasma and buffy coat and isolated erythrocytes were washed four to five times with $0.154 \mathrm{~mol} / 1 \mathrm{NaCl}$.

Determination of $\mathrm{AChE}$ activity Erythrocyte hemolysate was prepared as described by Beutler ${ }^{13}$. Packed RBC were suspended in $0.154 \mathrm{M} \mathrm{NaCl}$ and to this suspension, $\beta$-mercaptoethanol-EDTA stabilizing solution was added 
and the hemolysate was frozen overnight. The hemolysate was thawed preceding the experimental procedure. The membrane bound acetylcholinesterase activity in the human red blood cell was analyzed following the method of Ellman et al. ${ }^{14}$ as described in Beutler ${ }^{13}$. The reaction mixture composed of $1 \mathrm{~mol} / 1$ Tris $\mathrm{HCl}, 5 \mathrm{mmol} / 1$ EDTA with $0.5 \mathrm{mmol} / 1$ 5,5'-di-thiobis (2-nitro-benzoic acid) (DTNB) solution. The reaction was initiated by adding $0.01 \mathrm{~mol} / 1$ acetylthiocholine iodide and followed by reading at 412 nm. Hemoglobin was measured in red blood cell hemolysate as described by Beutler ${ }^{13}$.

Determination of MDA Content Erythrocyte MDA was measured according to the method of Esterbauer and Cheeseman ${ }^{15}$. Packed erythrocytes $(0.2 \mathrm{ml})$ were suspended in $3 \mathrm{ml}$ Krebs- Ringer phosphate buffer (KRP), pH 7.4. The lysate $(1 \mathrm{ml})$ was added to $1 \mathrm{~mL}$ of $10 \%$ trichloroacetic acid (TCA) and the mixture was centrifuged at $1000 \mathrm{~g}$ for $5 \mathrm{~min}$. The supernatant $(1 \mathrm{ml})$ was added to $1 \mathrm{ml}$ of $0.67 \%$ thiobarbituric acid (TBA) in $0.05 \mathrm{~mol} / 1$ $\mathrm{NaOH}$ and boiled for $20 \mathrm{~min}$ at $90^{\circ} \mathrm{C}$, cooled and the absorbance was read at $532 \mathrm{~nm}$ (OD1) and $600 \mathrm{~nm}$ (OD2). The net optical density (OD) was calculated after subtracting absorbance OD2 from OD1. The concentration of MDA in erythrocytes was determined from a standard plot. The concentration of MDA was expressed as nmol/ $\mathrm{ml}$ of packed erythrocytes.

Determination of total antioxidant capacity The total antioxidant capacity was measured in terms of Ferric Reducing Ability of Plasma (FRAP) by the method of Benzie and Strain ${ }^{16}$. Working FRAP reagent was prepared by mixing acetate buffer ( $300 \mathrm{mM}, \mathrm{pH} 3.6), 2$, 4, 6- tri [2-pyridyl]-s-triazine (10 mM in $40 \mathrm{mM} \mathrm{HCl}$ ) solution and $\mathrm{FeCl}_{3} \cdot 6 \mathrm{H}_{2} \mathrm{O}(20 \mathrm{mmol} / \mathrm{l})$ solution in 10:1:1 ratio respectively. $3 \mathrm{ml}$ of FRAP reagent was mixed with $100 \mu \mathrm{l}$ of plasma and the contents were mixed thoroughly. The absorbance was read at $593 \mathrm{~nm}$ at 30 second intervals for 4 minutes. Aqueous solution of known $\mathrm{Fe}(\mathrm{II})$ concentration in the range of $100-1000 \mu \mathrm{mol} / 1$ was used for calibration. Regression equation the FRAP values ( $\mu$ mol Fe (II) per 1) of the plasma was used for calculation.

Statistical analyses were performed using the software PRISM 4 (Graph pad Software Inc., San Diego, CA). The relationship among the various parameters was assessed using Pearson correlation coefficient $(r)$.

\section{RESULTS AND DISCUSSION}

Human erythrocytes undergo extensive structural, chemical, and metabolic changes during aging. Our results show a significant negative correlation $(\mathrm{P}<0.001$; $\mathrm{r}=-0.9218$ ) between erythrocyte membrane acetylcholinesterase activity and human age (Fig. 1). The study clearly indicates that the erythrocyte AChE activity decreases with increase in age of human subjects. The results are consistent with previous reports examining the relationship between aging and $\mathrm{AChE}$ activity in different brain regions ${ }^{17,}{ }^{18}$. Decline in cholinergic indices (choline acetyltransferase, $\mathrm{AChE}$, and muscarinic acetylcholine

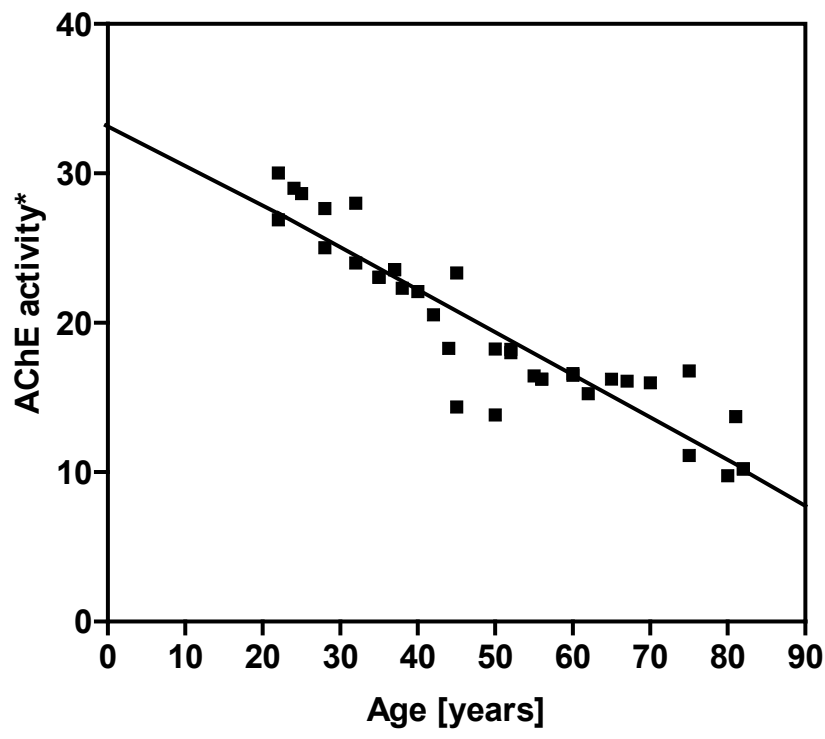

Fig. 1. Erythrocyte membrane bound acetylcholinesterase activity plotted as a function of human age. *Activity expressed as $\mu \mathrm{mol}$ acetylcholine iodide hydrolysed/min per gm haemoglobin at $37{ }^{\circ} \mathrm{C}$. $\mathrm{P}<0.001 ; \mathrm{r}=-0.9218$. Each point represents the mean of 3 experimental values.

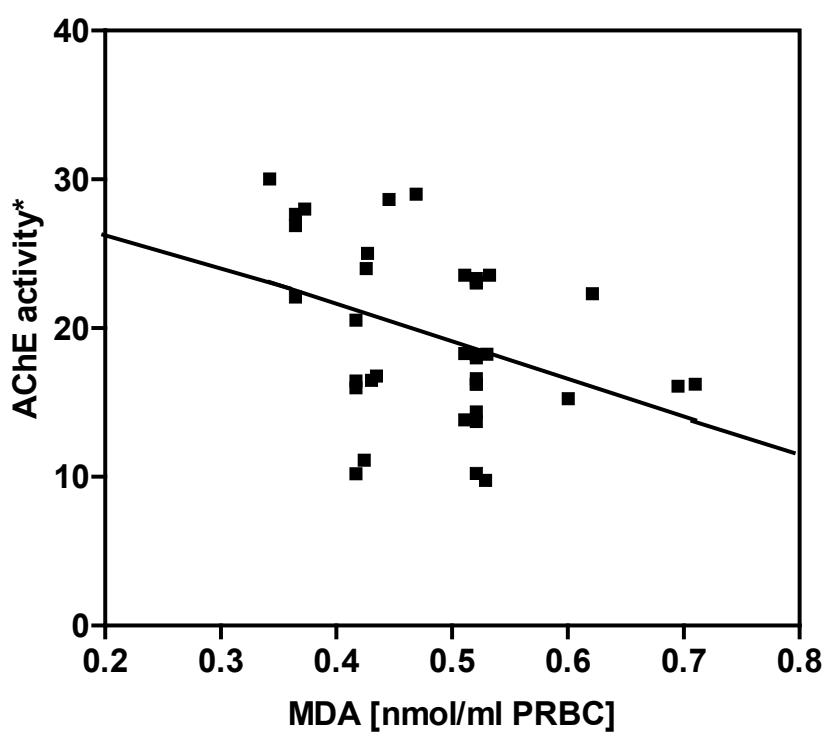

Fig. 2. Correlation plot between AChE activity and lipid peroxidation index (MDA). AChE activity expressed as $\mu \mathrm{mol}$ acetylcholine iodide hydrolysed/min per gm haemoglobin at $37^{\circ} \mathrm{C}$. MDA is expressed as $\mathrm{nmol} / \mathrm{ml}$ of packed erythrocytes. $\mathrm{P}<0.05 ; \mathrm{r}=-0.3791$.

receptors) has already been reported during normal aging process ${ }^{19}$.

Aging is the most important risk factor for Alzheimer's disease. Changes in cholinergic function have been characterized and a strong correlation has been observed with cognitive decline associated with aging. A low activity of $\mathrm{AChE}$ or cholinesterase present in cerebrospinal fluid of 


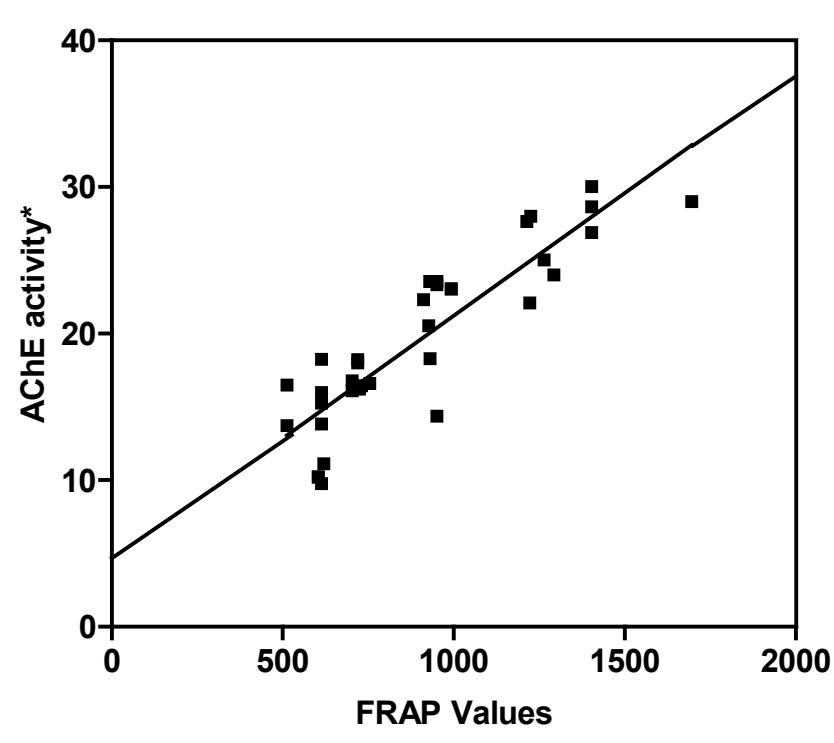

Fig. 3. Correlation plot between AChE activity and total antioxidant capacity of plasma (measured as FRAP). AChE activity expressed as $\mu \mathrm{mol}$ acetylcholine iodide hydrolysed/min per gm haemoglobin at $37^{\circ} \mathrm{C}$. FRAP values expressed as $\mu \mathrm{mol}$ Fe (II) per 1 of plasma. $\mathrm{P}<0.001 ; \mathrm{r}=-0.8837$.

a non-demented individual may indicate a brain at risk, or that the person is in the preclinical stage of dementia ${ }^{20}$.

The erythrocyte membrane is direct target of lipid peroxidation under oxidative stress that involves cleavage of polyunsaturated fatty acids at their double bonds leading to the formation of MDA. As lipid peroxidation of cell membranes increases, the polarity of lipid-phase surface charge and the formation of protein oligomers increase, and molecular mobility of lipids, number of -SH groups, and resistance to thermo denaturation decrease. Recent findings have emphasized the importance of lipid peroxidation in relation to the role of caloric restriction and the extension of longevity ${ }^{21}$. Fig. 2 shows the correlation between erythrocyte $\mathrm{AChE}$ and lipid peroxidation, measured in terms of MDA. We have already reported an age-dependent increase in $\mathrm{MDA}^{11}$. The decrease in AChE correlates significantly with increase in lipid peroxidation during human aging.

The activity of AChE depends largely on the membrane characteristics. It is known that AChE activity is modulated by the hydrophobic environment of the membrane and depends on the membrane fluidity and surface charge $^{22}$. Membrane fluidity, which is a key property of the membrane lipid bilayer, has been found to decrease with aging ${ }^{23}$. These changes may cause alterations in the physical properties of membranes resulting in modifications in enzymatic activity of membrane bound proteins and lipid-protein interactions. It has also been reported that AChE activity is influenced by membrane surface phenomena ${ }^{24}$. A decrease in the erythrocyte membrane sialic acid content has been reported during aging ${ }^{25}$, since sialic acid constitutes the principal charged component of the membrane, its loss from the erythrocyte surface during aging may be expected to reduce the total nega- tive charge on the surface of the erythrocytes, and consequently their membrane potential. Furthermore, it has been suggested that the insertion of membrane proteins into the membrane lipid core may be dependent on transmembrane potential ${ }^{26}$.

The correlation between antioxidant capacity and oxidative damage during aging has been reported in several tissues in different species ${ }^{27-29}$. Fig. 3 shows the correlation between erythrocyte $\mathrm{AChE}$ and total plasma antioxidant capacity, measured in terms of FRAP values. We have already reported significant age-dependent decline in plasma antioxidant capacity measured in terms of FRAP ${ }^{12}$. The decrease in AChE correlates significantly with decrease in the antioxidant capacity of the plasma during human aging.

A study carried out on red cells subfractionated on percoll density gradient on the basis of cellular age into old and young cell fractions, reported that old human red blood cells had significantly lower AChE activity compared to young human red blood cells of both the sexes. Based on this observation, it was suggested that AChE activity could be an excellent enzymatic marker for RBC aging in humans ${ }^{5}$ although the plasma activity of AChE has been shown to be unaffected by age in humans ${ }^{30}$. Our results show significant age-dependent decrease in the activity of membrane bound AChE in a mixed a population of red blood cells and is the first report of an agedependent decline in $\mathrm{AChE}$ in humans.

\section{CONCLUSION}

The decline in AChE activity with increasing human age seems to be closely correlated with increasing extracellular oxidative stress; since we also show the correlation of age related alteration in AChE with age dependent decline with total antioxidant capacity of plasma and with increased lipid peroxidation during human aging. Both decreased antioxidant defence along with alteration in membrane rheology during aging may contribute towards decreased activity of AChE activity in erythrocyte membrane. In the light of a number of reports emphasizing the contribution of cholinergic decline towards memory deficits observed in aging and Alzheimer's disease, our findings may help to explain the neuronal complications taking place under conditions of oxidative stress and aging, as well as in the development of dementia.

\section{REFERENCES}

1. Montine TJ, Neely MD, Quinn JF, Beal MF, Markesbery WR, Roberts LJ, et al. Lipid peroxidation in aging brain and Alzheimer's disease. Free Radic Biochem Med 2002; 33: 620-6.

2. Hald A, Lotharius J. Oxidative stress and inflammation in Parkinson's disease: is there a causal link? Exp Neurol 2005; 193 : 279-90.

3. Perry E, Court J, Goodchild R, Griffiths M, Jaros E, Johnson M, et al. Clinical neurochemistry: developments in dementia research based on brain bank material. J Neural Transm 1998; 105: 915-33.

4. Gsell W, Jungkunz G, Riederer P. Functional neurochemistry of Alzheimer's disease. Curr Pharm Des 2004; 10: 265- 93. 
5. Prall YG, Gambhir KK, Ampy FR. Acetylcholinesterase: an enzymatic marker of human red blood cell aging. Life Sci 1998; 63(3): 177-84.

6. Pradham SN. Central neurotransmitters and aging. Life Sci 1980; 26:1643-56.

7. Gorini A, Ghingini B, Villa RF. Acetylcholinesterase activity of synaptic plasma membranes during aging: effect of L-acetylcarnitine. Dementia 1996; 7:147-54.

8. Sorensen K, Gentinetta R, Brodbeck U. An amphiphile-dependent form of human brain caudate nucleus acetylcholinesterase: purification and properties. J Neurochem 1982; 39: 1050-60.

9. Kaizer RR, Correa MC, Gris LR, da Rosa CS, Bohrer D, Morsch VM, et al. Effect of long-term exposure to aluminum on the acetylcholinesterase activity in the central nervous system and erythrocytes. Neurochem Res 2008; 33(11): 2294-301.

10. Molochkina EM, Zorina OM, Fatkullina LD, Goloschapov AN, Burlakova EB. H2O2 modifies membrane structure and activity of acetylcholinesterase. Chem Biol Interact 2005; 157-158: 401-4.

11. Rizvi SI, Maurya PK. Markers of oxidative stress in erythrocytes during aging in humans. Ann N Y Acad Sci 2007; 1100: 373-82.

12. Rizvi SI, Jha R, Maurya PK. Erythrocyte plasma membrane redox system in human aging. Rejuvenation Res 2006; 9: 470-4.

13. Beutler E. Red cell metabolism: A manual of Biochemical methods. 3rd edition. Grune and Stratton Orlando; 1984.

14. Ellman GL, Courtney KD, Andres Jr V, Featherstone RM. A new and rapid colorimeteric determination of acetylcholinesterase activity. Biochem Pharmacol 1961; 7: 88-95.

15. Esterbauer H, Cheeseman KH. Determination of aldehydic lipid peroxidation products: malondialdehyde and 4-hydroxynonenal Methods Enzymol 1990; 186: 407-13.

16. Benzie IFF, Strain JJ. The ferric reducing ability of plasma (FRAP) as a measure of "Antioxidant Power": The FRAP assay. Anal Biochem 1996; 239(1): 70-6.

17. Das A, Dikshit M, Nath C. Profile of acetylcholinesterase in brain areas of male and female rats of adult and old age. Life Sci 2001; 68(13):1545-55
18. Skau KA, Triplett CG. Age related changes in activity of Fischer 344 rat brain acetylcholinesterase molecular forms. Mol Chem Neuropathol 1998; 35 (1-3):13-21.

19. Zhang X. Cholinergic activity and amyloid precursor protein processing in aging and Alzheimer's disease. Curr Drug Targets CNS Neurol Disord 2004; 3(2):137-52.

20. Shen ZX. The significance of the activity of CSF cholinesterases in dementias. Med Hypotheses 1996. 47(5):363-76.

21. Sanz A, Pamplona R, Barja G. Is the mitochondrial free radical theory of aging intact? Antioxid. Redox Signal 2006; 8: 582-99

22. Klajnert B, Sadowska M, Bryszewska M. The effect of polyamidoamine dendrimers on human erythrocyte membrane acetylcholinesterase activity. Bioelectrochem 2004; 65: 23-6.

23. Goi G, Cazzola R, Tringali C, Massaccesi L, Volpe SR, Rondanelli $\mathrm{M}$, et al. Erythrocyte membrane alterations during ageing affect beta-D-glucuronidase and neutral sialidase in elderly healthy subjects. Exp Gerontol 2005; 40(3): 219-25.

24. Livne A, Bar-Yaakow 0. Sensitivity of erythrocyte acethylcholinesterase to inhibition by linolenoyl sorbitol. Dependence on a transmembrane potential Biochim Biophys Acta 1976; 419: 358-64.

25. Mazzanti L, Rabini RA, Salvolini E, Tesei M, Martarelli D, Venerando B, et al. Sialic Acid, Diabetes, and Aging: A Study on the Erythrocyte Membrane. Metabolism 1997; 46 (1): 59-61.

26. Kempf C, Klausner RD, Weinstein JN, Van Renswoude J, Picus M, Blumenthal R. Voltage-dependent trans-bilayer orientation of melittin. J Biol Chem 1982; 257: 2469-76.

27. Inal ME, Kanbak G, Sunal E. Antioxidant enzyme activities and malondialdehyde levels related to aging. Clin Chim Acta 2001; 305 : 75-80.

28. Melov S. Animal models of oxidative stress, aging, and therapeutic antioxidant interventions. Int. J. Biochem. Cell Biol 2002; 34: 1395-400.

29. Barja G. Rate of generation of oxidative stress-related damage and animal longevity. Free Radic Biol Med 2002; 33: 1167-72.

30. Abou-Hatab K, O'Mahony MS, Patel S, Woodhouse K. Relationship between age and plasma esterases. Age Ageing 2001; 30 (1):41-5. 